\title{
CONTRIBUIÇÕES DA TEORIA HISTÓRICO- CULTURAL PARA O PROCESSO DE AVALIAÇÃO PSICOEDUCACIONAL
}

\author{
Marilda Gonçalves Facci ${ }^{1}$ \\ Universidade Estadual de Maringá \\ Nádia Mara Eidt ${ }^{2}$ \\ Universidade Estadual Paulista Júlio de Mesquita Filho \\ Silvana Calvo Tuleski ${ }^{3}$ \\ Universidade Estadual de Maringá \\ Universidade Estadual Paulista Júlio de Mesquita Filho
}

\begin{abstract}
Este artigo objetiva apresentar contribuições da psicologia históricocultural para a análise crítica da avaliação psicoeducacional tradicional e postular os fundamentos para uma nova modalidade avaliativa. Tal proposta se justifica mediante a atual revitalização do uso das testagens padronizadas para mensuração de funções psicológicas, devido à vulgarização da neuropsicologia. Historicamente, os testes padronizados têm servido como instrumento para atestar cientificamente a ideologia da igualdade entre os homens na sociedade capitalista que se mantém pela expropriação e exclusão. Além disso, existe forte tendência a esperar que
\end{abstract}

1 Endereço para correspondência: Rua Parque do Horto, 124, CEP 87060-285, Maringá, PR. Telefone: (44) 3261-4416. Endereço eletrônico: marildafacci@wnet.com.br

2 Endereço para correspondência: Rua Paulino Botelho de Abreu Sampaio, 1238, ap 01, CEP 13061-060, São Carlos, SP. Telefone: (16) 3372-3880. Endereço eletrônico: nadiaeidt@ig.com.br

3 Endereço para correspondência: Rua Francisco Glicério, 517, apto 22, CEP 87030050, Maringá, PR. Telefone: (44) 269-5754. Endereço eletrônico: silvanatuleski@teracom.com.br.

Psicologia USP, 2006, 17(1), 99-124 
seus resultados expliquem a inteligência como inata ou considerem as predisposições hereditárias para aprender, o que se contrapõe à compreensão de que funções mentais são formadas no processo de desenvolvimento histórico-social, mediante a apropriação da cultura humana. É necessário, portanto, uma avaliação que considere as mediações sociais (instrumentos e signos) como constituintes das funções psicológicas, promovendo desenvolvimento de todos os indivíduos e não legitimação da exclusão social.

Descritores: Psicologia educacional. Avaliação psicológica. Testes psicológicos.

\section{Introdução}

esde o nascimento da Psicologia científica, no final do século XIX, até o momento atual, os testes psicométricos vêm sendo instrumentos utilizados para auxiliar no diagnóstico da deficiência mental e dos distúrbios de aprendizagem, principalmente no contexto escolar. O processo de avaliação sempre esteve atrelado a uma das atribuições do psicólogo na escola, desde os primórdios da introdução da Psicologia no processo educativo. Alchieri e Cruz (2003) afirmam que a Psicologia se desenvolveu graças à sistematização de conhecimentos sobre processos psicológicos básicos e do uso de testes psicológicos para verificar os estágios de desenvolvimento e aprendizagem dos seres humanos.

Alchieri e Cruz (2003), ainda, fazendo uma revisão histórica acerca da avaliação psicológica no Brasil, afirmam que o período que compreende de 1836 à 1930 foi uma fase fecunda para o aprofundamento desses conhecimentos, tendo com referência estudos e publicações oriundos da produção médica, científica e acadêmica. $\mathrm{O}$ desenvolvimento da avaliação psicológica esteve vinculado ao desenvolvimento de pesquisas, do ensino de técnicas e procedimentos ligados aos instrumentos psicológicos em sua aplicação. Assim, podemos concluir que o uso de métodos quantitativos para mensurar a inteligência, conforme ressalta Mindrisz (1994), é quase tão antigo na história da Psicologia quanto o seu surgimento enquanto ciência. 
Contribuições da Teoria Histórico-Cultural para o Processo de Avaliação...

Na atualidade, com a crescente vulgarização da neuropsicologia, principalmente a norte-americana, temos assistido uma revitalização do uso das testagens padronizadas para mensuração de funções psicológicas. O Quociente de Inteligência (QI) é ainda amplamente utilizado, não só no diagnóstico da deficiência mental, como na predição do sucesso ou fracasso escolar da criança avaliada, apesar das críticas existentes acerca das limitações destes instrumentos e das classificações da inteligência deles decorrentes, conforme podemos constatar em Collares e Moysés (1997) e Machado (2000). Para Beáton (2001), as pesquisas atuais têm se voltado mais para tecerem críticas acerca das técnicas de medição em Psicologia e Pedagogia do que para estudar seus efeitos positivos e negativos, elaborando uma orientação sobre seu emprego, seus limites e possibilidades. Embora entendamos que as críticas sejam fundamentais para a superação de antigas práticas avaliativas, neste artigo pretendemos oferecer uma alternativa que vá além destas, destacando as possibilidades de uma outra forma de avaliação, utilizando como referencial a Psicologia Histórico-Cultural.

\section{Considerações acerca da avaliação psicológica tradicional e os pressupostos que a embasam.}

Vários autores (Bissoli Neto, 1997; Collares \& Moysés, 1997; Machado, 2000; Souza, 1997) já trouxeram importantes contribuições aos estudos sobre as avaliações psicoeducacionais no Brasil, abordando tanto a incoerência de procedimentos utilizados por psicólogos, quanto os efeitos de práticas inadequadas para as crianças a elas submetidas, o que nos convida a repensar a formação e atuação dos profissionais da Psicologia.

Machado (2000), por exemplo, procurou discutir o objetivo e a função das avaliações psicológicas. Em sua pesquisa verificou que $84,2 \%$ das crianças encaminhadas para tal avaliação não revelaram, durante esse processo, os motivos que justificariam a necessidade da mesma. Concluiu que se a criança pode agir e produzir de maneira diferente daquela que acontece em sala de aula, não se pode falar de algo crônico e individualizado em seu corpo. 
Outro estudo de caráter denunciatório foi realizado por Bissoli Neto (1997). Ele demonstra que, na época, no Estado de São Paulo, um elevado número de crianças, em torno de 55\%, foi inserido erroneamente em classes especiais com o aval de profissionais da Psicologia, contribuindo assim para a legitimação da exclusão desses alunos do ensino regular.

Em outra pesquisa, Souza (1997) analisou os encaminhamentos para atendimento psicológico nas UBSs da região Sudeste de São Paulo, registrando a conduta geralmente utilizada por psicólogos lotados nestes locais para atendimento da queixa escolar, que se baseava em: entrevista inicial, aplicação de testes padronizados, encaminhamento para psicoterapia e orientação a pais, sendo que em um número reduzido de casos (5,8\%) foram constatadas algumas orientações à professora que encaminhou a queixa. Observou, ainda, que os pressupostos teóricos utilizados pelos psicólogos para realizar as avaliações pautavam-se predominantemente em uma perspectiva psicométrica ou psicanalítica dos problemas de aprendizagem, contribuindo para a manutenção da visão medicalizante e/ou psicologizante do processo de aprendizagem.

Acreditamos que os resultados destas três pesquisas, mesmo ao se referirem a contextos específicos, lançam luz para a análise das contradições de avaliações psicoeducacionais acríticas e descontextualizadas, que avalizam o fracasso escolar como decorrente de problemas individuais.

Essa forma de compreensão dos fenômenos escolares esteve presente já na constituição da Psicologia como ciência, em um momento em que se tinha como meta a manutenção da ordem e o controle, evidenciando seu compromisso com o projeto social burguês e com as regras do capitalismo. Deste modo, fundamentou-se em uma visão organicista, amparada na Biologia; em uma visão clínica de trabalho, centrando-se no diagnóstico e tratamento dos problemas de aprendizagem; bem como em uma "visão psicometrista que seleciona os mais 'aptos', depositando no aluno a culpa pelo 'não aprender’” (Facci, 2001, p. 75).

Os dados acima descritos indicam que essa concepção individualizante e patologizante acerca do fracasso escolar por parte dos profissionais da 
Contribuições da Teoria Histórico-Cultural para o Processo de Avaliação...

Psicologia ainda não foi superada. Tal concepção permeia os estudos realizados sobre o fracasso escolar, como bem explicitado em pesquisa realizada por Angelucci, Kalmus, Paparelli e Patto (2004). A prática apoiada em tais pressupostos termina por legitimar a continuidade do processo de transferência de questões pertencentes ao âmbito da sociedade para a educação, desta para a saúde e, em última instância para o próprio aluno que não aprende.

Outra importante contribuição fornecida pelas pesquisas acerca da avaliação psicoeducacional refere-se à denúncia do caráter ideológico dos testes psicométricos. Implicitamente, a testagem formal tem como base uma determinada concepção de homem e de sociedade, que generaliza comportamentos, habilidades e conhecimentos de uma determinada classe social, às outras classes sociais. A padronização dos testes psicológicos tem desconsiderado as desigualdades sociais e culturais existentes em nosso sistema capitalista. Os testes avaliam as capacidades das crianças como se elas fossem desvinculadas de uma realidade histórica e cultural. Nesse sentido, Machado (2000) afirma que se tornou "natural" acreditar na possibilidade de medirmos a inteligência e a capacidade individual das pessoas como se estas fossem construídas fora das relações sociais. Entretanto, quando é apresentada ao psicólogo uma queixa escolar, esta é constituída por uma história coletiva e a avaliação implica em buscar o quanto é possível alterar a produção dessa queixa. A esse respeito, Collares e Moysés (1997, p. 130) afirmam que os testes psicológicos, sempre padronizados nos estratos sociais superiores, são utilizados na avaliação de qualquer indivíduo, independentemente de sua classe social, pois acredita-se que "se está avaliando a inteligência, que transcende a própria vida”.

Os testes padronizados são construídos a partir da premissa de que todas as crianças avaliadas por esses instrumentos tiveram oportunidades equivalentes para se apropriarem do conhecimento exigido em tais provas. Na medida em que esse pressuposto não é verdadeiro, quaisquer inferências derivadas desses testes devem ser consideradas problemáticas (Campione, 2002). Em uma sociedade capitalista como a nossa, cuja marca é a expropriação e a exclusão, podemos concluir que os testes psicológicos tal como ainda vêm sendo utilizados, têm servido como um instrumento para atestar 
cientificamente o postulado ideológico da igualdade entre os homens, justificando as diferenças como problemas individuais de ordem orgânica e avalizando a exclusão dentro e fora do sistema escolar.

Além disso, geralmente as provas avaliam conhecimentos prévios e não a inteligência de uma criança. Embora concordemos que para aprender determinado conhecimento foi necessário certo grau de inteligência, este fato não torna iguais requisitos e resultados.

Beáton (2001) afirma existir uma forte tendência a esperar que o resultado dos testes forneça a inteligência inata ou as predisposições hereditárias da personalidade. Tal concepção contribui para a estigmatização dos indivíduos, uma vez que as pessoas que atingem um baixo desempenho em tais provas são freqüentemente consideradas como possuidoras de uma herança biológica fatal, fixa e imutável. Essa concepção se contrapõe à compreensão de que as funções mentais são formadas no processo de desenvolvimento histórico-social e se reproduzem nos indivíduos mediante um processo de apropriação do patrimônio cultural produzido pelas gerações anteriores (Leontiev, 1991). Deste modo, os testes psicológicos em sua forma de aplicação tradicional, têm sido caracterizados por sua função classificatória, seletiva e discriminatória.

Um outro ponto a ressaltar das avaliações formais está em sua rigidez e fixidez. Vigotski4 e Luria (1996) criticaram, os testes psicológicos padronizados devido à sua dimensão estática e não dinâmica, em que se mede apenas a quantidade de conhecimento ou habilidades que se encontram no nível real de desenvolvimento da criança, ao eliminarem a dimensão interativa e mediada. Lunt (1994) reforça esta crítica ao afirmar que no modelo de avaliação tradicional, o desempenho da criança é centrado na quantificação de erros e acertos, desconsiderando o processo vivenciado pelo indivíduo na resolução dos problemas propostos durante o teste. Para eles, portanto, esta

4 Optamos por escrever Vigotski como no ocidente, mas manteremos a grafia original das traduções nas referências 
Contribuições da Teoria Histórico-Cultural para o Processo de Avaliação...

forma de avaliação demonstra apenas o que a criança é capaz de fazer sozinha, sem o auxílio ou mediação de outrem, isto é, o que já está desenvolvido, ignorando o que está em processo de desenvolvimento. Em termos educativos, o que isso nos traz? De que adianta constatar, mediante uma classificação do Quociente de Inteligência, que determinadas crianças estão abaixo da média? Isso significaria a existência de um padrão de desempenho geral, independente de cultura e classe social? Tal avaliação permite traçar um plano de trabalho com esta criança, que auxilie na reversão do diagnóstico inicial?

Da forma como vem sendo realizada, portanto, a avaliação psicoeducacional pouco contribui para traçar objetivos pedagógicos capazes de reverter o caminho de fracasso que algumas crianças passam a trilhar. Sem uma referência ou parâmetro que permita ao professor elaborar planos de trabalho eficazes, este se sente desorientado e, muitas vezes, desobrigado de um investimento pedagógico diferenciado, pois se os testes medem funções inatas, consideradas como imutáveis ou irreversíveis, não haveria mais condição para um trabalho educativo.

Quando as avaliações psicológicas restringem-se apenas aos conhecimentos que estão na zona de desenvolvimento real, em nada contribuem para que se compreenda como os alunos estão utilizando voluntariamente suas funções psicológicas superiores, funções essas que são formadas a partir da mediação de instrumentos e signos culturais, vitais para a apropriação do conhecimento e, conseqüentemente, para o desenvolvimento do indivíduo. Se, para Vigotski, aprendizagem promove desenvolvimento e este, por sua vez, provoca novas aprendizagens, numa relação dinâmica, é imprescindível que sejam revistos fundamentos e parâmetros das técnicas utilizadas para avaliar a aprendizagem e o desenvolvimento infantil. 
Marilda Gonçalves Facci, Nádia Mara Eidt e Silvana Calvo Tuleski

\section{Reeditando as críticas de Luria, Vigotski e Leontiev aos testes padronizados.}

Estes autores, fundadores da Psicologia Histórico-Cultural já postulavam, na primeira metade do século XX, que era mais importante para a Psicologia considerar adequadamente as complexidades qualitativas do comportamento, do que promover uma falsa impressão de rigor conceitual que a avaliação tradicional oferecia (Luria, 1969). As investigações realizadas pela Troika em relação ao desenvolvimento das funções psicológicas superiores em crianças normais e deficientes, bem como sua perda em danos cerebrais, conduziram à rejeição completa do uso de testes psicométricos e formais para dar um diagnóstico seguro, por definirem graus de subdesenvolvimento mental ou a extensão do defeito em termos apenas quantitativos. A tarefa principal da investigação psicológica, para eles, deveria estar pautada em uma definição precisa do problema, isto é, no estudo concreto da mudança qualitativa na estrutura dos processos psíquicos que resultam de uma determinada condição patológica do cérebro. Entendiam tal postura como necessária porque os sintomas externos raramente eram suficientes para permitir um julgamento imediato sobre os mecanismos fisiológicos que estão por detrás de determinado comportamento, sendo que uma descrição superficial simples dos mesmos sem sua interpretação e análise psicológica poderia conduzir a erros clínicos sérios (Luria, 1957).

Foi partindo de uma análise qualitativa cuidadosa da gênese de cada síndrome patológica e seus mecanismos, que os psicólogos soviéticos tornaram-se capazes de fazer um trabalho de restauração de funções perturbadas por uma condição patológica, trabalho desenvolvido amplamente, na URSS, durante a Segunda Guerra Mundial.

Para Luria (1957), uma perturbação de funções só poderia ser restabelecida se o investigador se familiarizasse com o desenvolvimento das mesmas, qualificando-as ao observar suas peculiaridades quando comprometidas por uma lesão com devida clareza. A ignorância sobre a constituição de uma determinada função que fora transtornada impossibilitaria o clínico ou pedagogo de desenvolver métodos eficazes para seu restabelecimento. 
Contribuições da Teoria Histórico-Cultural para o Processo de Avaliação...

Para Luria e Majovski (1977), as baterias de testes nos Estados Unidos se desenvolveram à parte da necessidade de se combinar e compreender 0 conjunto dos dados estandartizados, pois se pautavam numa visão atomizada das funções. A necessidade de padronização conduziu ao uso de uma bateria integrada de testes administrados do mesmo modo e cuidadosamente sistematizados a todos os pacientes avaliados, com o objetivo de obter confiabilidade. Se o examinador decide confiar em uma bateria de testes para selecionar os pacientes clínicos, deve ser esta uma bateria múltipla que ajude no diagnóstico e possibilite uma linha de base, ofereça dados para planejamento do tratamento de acordo com as necessidades de cada paciente, critérios que, segundo ele, nenhuma bateria norte-americana até a década de 1970, satisfazia. Alguns ideólogos destas formas de avaliações padronizadas, segundo Luria e Majovski (1977), indicavam que os testes deviam ser aplicados sem que houvesse um conhecimento anterior da história do paciente ou de qualquer resultado médico antecedente, na tentativa de eliminar o aspecto subjetivo do avaliador. Porém, para eles, a interpretação subjetiva não pode ser evitada deliberadamente, pois esta é baseada na experiência clínica do intérprete ao fazer avaliações e tais tentativas apenas afirmam uma pseudoneutralidade, uma crença quase que mágica nos instrumentos em si.

O principal esforço destes psicólogos estava em elaborar uma teoria que oferecesse uma base sólida para o entendimento da organização funcional dos sistemas individuais do cérebro, que envolvem e regulam a atividade psicológica humana. Por isso, os estudos das funções corticais e dos processos psicológicos que afetam o comportamento humano quando transtornados devido a uma lesão localizada estiveram em grande parte baseados no método "qualitativo" de investigação, isto é, em uma descrição clínica que usava uma prática flexível, mas sistemática de provas, sendo fortemente oposta ao método psicométrico quantitativo, que assegurava que para todas as funções e habilidades há um padrão normativo ou uma média, a qual todos os indivíduos deviam ser comparados.

Para Luria e Majovski (1977), uma média da população não poderia ser um padrão apropriado de comparação, pois não se aplicava ao caso de um paciente individual que precisava ser reabilitado. Os dados clínicos devi- 
am ser usados para se formular uma hipótese de funcionamento do paciente que estava apresentando problema, em contraposição a uma aproximação “cega” oferecida pela quantificação. O enfoque, para ele, devia ser "dinâmico”, flexível, em contraste com o dos testes padronizados e quantitativos, pois cada paciente deveria ser considerado como alguém em transformação, isto é, uma experiência dinâmica, que devia ser teoricamente fundamentada nos efeitos para o seu comportamento de um distúrbio do cérebro, construindo-se um quadro clínico dos defeitos com precisão e monitorando quaisquer mudanças no repertório comportamental do paciente. Somente assim os resultados poderiam ser aproximados, então, com outros casos semelhantes avaliados para se obter uma comparação intersubjetiva com propósitos de generalização (Luria \& Majovski, 1977).

Tendo por base o exposto acima, em estudos desenvolvidos por Luria com lesionados de guerra, é possível estabelecer alguns pressupostos da avaliação qualitativa defendida pelos soviéticos, que podem ser estendidas para a avaliação psicoeducacional, tema deste artigo: é uma avaliação detalhada, dinâmica e flexível, baseada na aproximação investigativa, com aplicação de provas diversas dirigidas aos diferentes aspectos do comportamento; os dados obtidos são comparados com os dados da linha base, buscandose o "elemento comum" que está por debaixo dos tipos diferentes de sintomas manifestos em formas variadas no comportamento do paciente; realizase uma série de replicações e um estudo dos resultados obtidos, requerendo flexibilidade de pensamento do investigador, uma capacidade crítica para rejeitar hipóteses não apoiadas pelos dados, bem como para se chegar à qualificação dos sintomas primários e identificação da síndrome.

Desta forma, a qualificação de um sintoma proposta por Luria e Majovski (1977) nunca pode ser interpretada como a aplicação mecânica de uma bateria de teste unificada, com interpretação quantitativa formal dos resultados, pois é um esforço clinicamente criativo que requer um pensamento crítico, com atenção particular não só ao conteúdo das respostas produzido pelo paciente, mas para a forma como são expressas. Assim, a atenção não deve estar focada em primeira mão no que sofre (estrutura ou função), mas sim em como uma função sofre, sendo esta a essência do que 
Contribuições da Teoria Histórico-Cultural para o Processo de Avaliação...

significa o termo qualificação dos sintomas (Luria \& Majovski, 1977). Da mesma forma, na avaliação psicoeducacional, tem-se que atentar para a análise qualitativa das respostas e comportamentos dos alunos.

O método cego de interpretação de testes unificados sem conhecimento anterior da história do paciente, baseada apenas em dados clínicos quantitativamente acumulados não serve a uma análise completa e ao diagnóstico de lesões do cérebro, bem como para recomendações de tratamento, pois cria apenas uma falsa ilusão de segurança e fidedignidade ao psicólogo inexperiente (Luria \& Majovski, 1977). O mesmo se pode afirmar com relação à avaliação psicoeducacional, na qual, muitas vezes, deixa-se de compreender o contexto em que a queixa escolar foi produzida, analisando-se tão somente o que o aluno apresenta nos testes, desconsiderando fatores histórico-sociais que têm produzido o fracasso escolar.

Quando transpomos todas estas críticas realizadas por Luria em relação à neuropsicologia ao processo de avaliação de crianças e adolescentes com problemas de escolarização, parece-nos que o quadro é ainda mais grave, pois os testes padronizados quantitativos são realizados para diagnosticar e encaminhar crianças organicamente saudáveis, por meio da aproximação cega a padrões de normalidade que desconsideram a relação dialética entre o meio social e cultural e o organismo individual. Permanece então a pergunta em relação aos objetivos de tal avaliação: avaliar para classificar e segregar ou avaliar para recuperar e promover desenvolvimento? Nesse sentido, as considerações de Leontiev (1991, pp. 59-60) acerca da avaliação psicológica ganham notável atualidade:

... que valor tem as investigações de médicos e psicólogos sobre o problema do atraso mental? A que resultado final conduzem os seus diagnósticos e prognósticos, os seus métodos de seleção? Podem conduzir à diminuição do número de crianças classificadas como mentalmente subdesenvolvidas, ou determinam talvez o resultado oposto?

Leontiev (1991) afirma que as informações advindas da testagem psicométrica apenas fornecem uma idéia superficial do nível de desenvolvimento da criança, além de trazer a ilusão de uma explicação sobre a natureza do atra- 
so, já que se apóia na "teoria dos dois fatores”. Segundo essa teoria, o desenvolvimento mental de uma criança é determinado pela predominância de fatores endógenos e/ou exógenos, ou seja, pelo papel desempenhado pelo meio social e pelas determinações biológicas nesse desenvolvimento. Chega-se, no melhor dos casos, a uma tentativa de conciliação entre os pólos dessas dicotomias, explicação que evidentemente se distancia de uma perspectiva histórico-social da constituição do indivíduo.

De acordo com aqueles pressupostos, se uma criança apresenta um atraso, ele é considerado em relação às outras crianças da mesma idade, que possuiriam a priori condições semelhantes de aprendizagem e desenvolvimento, tornando-se impossível atribuir o atraso ao fator ambiental. Um outro fator que reforça a idéia de que o atraso possa ser explicado facilmente a partir de fatores endógenos é que muitas crianças mentalmente atrasadas não apresentam características patológicas observáveis, visíveis em seu organismo. Buscam-se então os fatores internos que poderiam explicar seu atraso, como por exemplo, a inteligência geral, e, para confirmar essa hipótese, lança-se mão dos testes de inteligência.

Leontiev (1991) evidencia a necessidade de considerar o desenvolvimento da criança sob novas perspectivas. Nesse sentido, alerta para a gravidade do fato de que muitas vezes o futuro de uma criança é decidido tendo por base um determinado coeficiente de inteligência, mesmo diante da comprovação da existência de variações nesses coeficientes. Para ele, o professor deve levar em consideração o processo de formação das operações de pensamento das crianças, visando a seu desenvolvimento mental. Esse processo tem início com a formação de ações mentais externas com objetos externos e não mediante o ensino de generalizações. Assim, devem-se mostrar as ações a realizar e seus resultados para que, gradativamente, a criança comece a realizar essas ações de maneira independente, transferindo-as para o plano da linguagem e tornando-as verbalizadas. Por exemplo, a criança começa a contar em voz alta e já não precisa mais fazer uso dos dedos para realizar a tarefa de contagem, como ocorria no início desse processo. Na etapa seguinte, a ação é transferida em seu conjunto para o plano mental, tornando-se interna e a criança passa a ser capaz de contar mentalmente. 
Contribuições da Teoria Histórico-Cultural para o Processo de Avaliação...

Leontiev (1991) demonstra, pois, que o ensino adequadamente organizado é capaz de promover alterações significativas no desenvolvimento e na aprendizagem de crianças consideradas mentalmente atrasadas. Em uma escola, observou que alguns alunos usavam os dedos às escondidas para fazer operações mentais e sua análise foi de que estavam na etapa da operação externa de usar objetos para contagem, isto é, não haviam passado para a etapa seguinte. Para fazê-lo, era necessário regressar à etapa das próprias operações externas, "condensando” corretamente essas operações, transferindo-as para o plano da linguagem e reorganizando a capacidade de "contar mentalmente”. Essa reorganização nas operações mentais ocorre até mesmo em crianças muito atrasadas e, em casos em que se verifica que o atraso é menor, chega-se a sua completa eliminação. Vale ressaltar que, se uma intervenção como essa não fosse realizada no seu devido tempo, o processo de formação das operações mentais poderia ser formado de maneira inadequada e se teria a impressão de que a criança sofre de um atraso intelectual.

Verifica-se que as causas do atraso mental não podem ser explicadas somente a partir de anamneses, entrevistas e testagens psicométricas, ou seja, com instrumentos que buscam as causas do não aprender na criança e em sua família, mas essa análise deve ser ampliada para a atividade de ensino e de aprendizagem, especialmente no que se refere à qualidade do conteúdo ministrado, a relação professor-aluno, a metodologia de ensino, a adequação de currículo, o sistema de avaliação adotado, em suma, o acesso da criança ao mundo dos instrumentos e signos culturais.

\section{Avaliação psicoeducacional dinâmica e mediada}

Após as críticas realizadas à forma pela qual a avaliação tem sido realizada e a apresentação de alguns aspectos valorizados na avaliação pelos autores soviéticos, passemos à discussão da avaliação mediada e assistida, que busca fundamentos na Psicologia Histórico-Cultural. Essa forma de avaliação começou a ser utilizada no Brasil, a partir da década de 1990, e é caracterizada por Linhares (1995, p. 24), da seguinte forma: 
... um conjunto de estratégias instrucionais utilizadas durante o processo de avaliação, a fim de garantir o fornecimento de ajuda, melhorando as condições da situação de avaliação, para que o examinando possa revelar o seu desempenho potencial e possa atingir um grau crescente de autonomia em situações de resolução de problemas.

Linhares (1995) esclarece que a avaliação estática se caracteriza pelos seguintes aspectos: a) tem instruções-padrão de como o examinador deve agir, isto é, tem o seu comportamento pautado por intervenções previsíveis; b) avalia produtos de aprendizagens realizadas até então pelo examinando, enfatizando as oportunidades passadas de aprendizagem; c) obtém escores e comparações do indivíduo com seu grupo de referência. A avaliação assistida caracteriza-se da seguinte maneira: a) há flexibilidade das instruções durante a avaliação, regulada pelo desempenho do examinando, incluindo-se um componente de ensino, de instruções adicionais e, portanto, havendo uma verificação de mudança em função da aprendizagem; b) avalia mais como o examinando adquire conhecimento e resolve problemas, focalizando mais a oportunidade presente de aprendizagem; c) obtém indicadores do processo de aprendizagem do indivíduo, sendo o indivíduo seu próprio controle.

De acordo com Linhares (1995), a avaliação dinâmica pode complementar e não substituir os testes de QI e sua contribuição mais significativa advém da possibilidade de fazer uma sondagem da sensibilidade do examinando à instrução, de identificar as estratégias cognitivas que ele usa para a solução de tarefas e de verificar a possibilidade de o mesmo modificar seu desempenho na própria situação de avaliação, assim como estimar o potencial de transferência e generalização de aprendizagem. Tal proposta, embora consista em um inegável avanço em relação às modalidades tradicionais de avaliação, ainda atribui aos testes psicométricos um papel central no processo avaliativo, pois as provas qualitativas são consideradas apenas complementares do processo, o que significa, ainda, a manutenção da idéia de confiabilidade dada à quantificação ou padronização, nem que seja para se comparar resultados das testagens formais e não-formais.

Lunt (1994), no entanto, diz que a avaliação dinâmica oferece uma abordagem alternativa e não complementar para a complexa tarefa da avali- 
Contribuições da Teoria Histórico-Cultural para o Processo de Avaliação...

ação, com potencial para superar alguns problemas inerentes às formas estáticas tradicionais de avaliar. Isto é, partindo de pressupostos vigotskianos seria impossível eliminar do processo avaliativo a mediação de signos e instrumentos, bem como a interação humana, pois desde os primeiros dias de desenvolvimento, as atividades de uma criança adquirem significado próprio em um sistema de comportamento social e, estando dirigidas para um objetivo definido, são refratadas pelo prisma do ambiente em que vive, fato que não pode ser ignorado no processo de avaliação.

\section{Estabelecendo novos pressupostos para constituir uma nova prática avaliativa}

Quando tomamos como base um paradigma de análise não biologicizante ou naturalizante, deslocamos a discussão do âmbito individual para o âmbito social, como é o caso já demonstrado da Psicologia HistóricoCultural. Se partirmos do pressuposto de que o desenvolvimento das funções psicológicas superiores como a atenção voluntária, vontade ou volição, percepção, pensamento abstrato, memória, isto é, todas as funções superiores, só são capazes de se desenvolverem em sua forma absoluta a partir de mediações culturais, o foco do problema sobre as incapacidades de aprendizagem desloca-se do nível individual para o social. Assim, passa a ser inevitável a discussão sobre a qualidade das mediações que, a sociedade atual vem exercendo, dentro e fora da escola, que, ao invés de promover a transição das funções psicológicas primitivas ou inatas (biológicas) às funções superiores (culturais) nos indivíduos, vêm dificultando tal processo em um número cada vez maior de crianças, adolescentes e adultos. E a avaliação psicoeducacional, nesta ótica, também deve ser alterada de forma radical.

Para Vigotski é a situação social do desenvolvimento que deve ser tomada como ponto de partida para todas as mudanças dinâmicas que ocorrem no desenvolvimento da criança. Desta forma, a avaliação não pode permanecer nos limites das ações individuais e autônomas da criança e em contextos restritos. O desenvolvimento dos homens incluídos nas condições 
da sociedade civilizada moderna não pode ser reduzido ao desenvolvimento de processos inatos naturais e a mudanças morfológicas condicionadas pelo mesmo, pois neste desenvolvimento incluem-se a mudança dos grupos sociais e das formas civilizadas, bem como os métodos que auxiliam a criança a se adaptar às condições da comunidade civilizada que a cerca. Interessa, portanto, compreender como a criança está utilizando as ferramentas culturais criadas pelos homens.

De acordo com Luria (1994), as ferramentas usadas não só geram mudanças radicais nas condições de existência do homem, mas agem sobre ele, efetuando uma mudança em sua condição psíquica. Nas inter-relações complexas com o ambiente, sua organização está sendo refinada e diferenciada; a mão e o cérebro vão assumindo formas definidas e diversos métodos complexos de conduta vão evoluindo, permitindo uma adaptação perfeita do homem em relação ao meio, quanto deste último ao primeiro. Assim, novas formas de conduta desenvolvem-se na criança, em primeiro lugar, devido às demandas feitas pelo ambiente a ela, sendo que estas demandas e condições são precisamente os fatores que ou podem estancar ou podem estimular o seu desenvolvimento, pois quando se exige da criança que trabalhe novas formas de adaptação, ocorrem súbitas transformações em seu desenvolvimento que são “formações indubitavelmente culturais” (Luria, 1994, p. 46).

Compare a conduta de um aluno no primeiro ano na escola com a de um aluno de pré-escola. Compare o curso dos processos mentais destes dois, e você notará duas estruturas em princípio essencialmente diferentes. Compare um menino de aldeia com outro menino da mesma idade que vive em uma cidade, e você será golpeado por uma diferença enorme na mentalidade de ambos, a causa da diferença funcional não está tanto no desenvolvimento psíquico natural (memória absoluta, a rapidez de reações, etc.) como no âmbito da experiência cultural deles e dos métodos que são usados por ambos, que vão além de suas habilidades naturais. (Luria, 1994, p. 47)

Na realidade, a avaliação tem que contemplar o desenvolvimento cultural da criança, as exigências que são feitas no seu entorno social, que produzem este ou aquele comportamento, pois não se trata como vimos enfatizando, de considerar somente os aspectos biológicos, mas sim, de estabelecer o que a 
Contribuições da Teoria Histórico-Cultural para o Processo de Avaliação...

cultura provoca em termos de desenvolvimento psicológico, que tipos de instrumentos a criança utiliza para resolver as atividades propostas e de que forma. Ao investigar o desenvolvimento do comportamento instrumental na criança, Luria (1994) concluiu que este passa por diversas fases, que podem ser sinteticamente resumidas em: 1) a criança não está em condições para executar a tarefa através de meios auxiliares complexos, ou seja, é incapaz de considerar os objetos oferecidos como meios auxiliares, denominada de fase pré-instrumental; 2) a criança começa a usar os objetos oferecidos como meios para atingir o objetivo, mas o faz sem estabelecer uma conexão racional entre a tarefa e os meios auxiliares, atuando como se estes fossem algo mágico, sendo tal "método" inadequado e o resultado a desaponta, fase denominada de mágica ou pseudo-instrumental, e; 3) posteriormente, observamos a fase instrumental real, cuja característica principal está na estrutura complexa de atos de comportamento, isto é, na habilidade para adaptar-se às tarefas difíceis, usando meios adequados e estímulos auxiliares exteriores, sendo esta a parte fundamental do comportamento que desenvolve a maioria dos escolares até chegar ao homem civilizado moderno.

Para Luria (1994), a análise científica das leis que subjazem o comportamento cultural da criança pode auxiliar a moldar uma série de medidas pedagógicas e didáticas concretas, bem como uma série de provas que, em vez de avaliar as qualidades naturais da criança, sejam dedicadas à análise do grau de utilização das ferramentas ou mediadores culturais. Medidas precisas destas características, ignoradas nas avaliações tradicionais, passam a ter a maior importância pedagógica. Isso decorre do fato de que, ao contrário dos demais animais superiores, no homem acontece uma conexão funcional complexa entre fala, o uso de ferramentas e o campo visual natural e, sem a análise desta ligação, a psicologia das atividades práticas do homem permaneceria incompreensível. A formação da unidade humana complexa de fala e atividade é produto de um processo profundamente arraigado de desenvolvimento no qual a história individual é unida de perto à história social (Vigotski \& Luria, 1994).

Quando a criança introduz a ação de outra pessoa, conscientemente, em suas tentativas para resolver um problema, começando não só a planejar 
a sua atividade mentalmente, mas também a organizar o comportamento da outra pessoa conforme as exigências do problema e criando condições seguras para solucioná-lo, aplica uma atitude social para si mesma, transfere uma forma social de comportamento para sua própria organização psicológica. Assim, a fonte da ação inteligente e do controle do seu próprio comportamento na solução de um problema prático complexo não é invenção de atos puramente lógicos. Somente a constituição de tal estrutura psicológica faz desaparecer as relações primárias entre percepção e movimento, através da inclusão dos estímulos de fala funcionalmente novos - sinais -, possibilitando a superação das formas primitivas de comportamento, indispensável ao desenvolvimento das funções psicológicas superiores, especificamente humanas (Vigotski \& Luria, 1994).

Assim, para Vigotski e Luria (1994), é o uso de sinais auxiliares que destrói a fusão do campo sensório com o sistema motor (comum nas demais espécies), colocando um tipo de "barreira funcional" entre os momentos primários e finais das reações que substituem ou alteram a reação da esfera motora para circuitos preliminares, alcançados com a ajuda do sistema psicológico superior. A criança, que antes resolvia o problema impulsivamente, passa a resolvê-lo internamente, por meio da conexão entre o estímulo e o sinal auxiliar correspondente, reconstruindo o processo psicológico inteiro através da linguagem que domina seu movimento em fundamentos totalmente novos.

A inclusão desta "barreira funcional" transfere o complexo processo reativo da criança para outro curso. Exclui as tentativas impulsivas, principalmente afetivas, e distingue o comportamento primitivo dos animais do comportamento intelectual do homem, pois este passa a ser baseado em combinações simbólicas preliminares. O movimento se separa da percepção direta e se submete a funções simbólicas incluídas no ato de reação, freando assim a história natural do comportamento e virando uma página nova: o da atividade intelectual superior do homem.

A "barreira funcional” entre percepção e motricidade, que tem sua origem na intrusão da palavra ou algum outro símbolo entre os pontos iniciais e finais da ação, explica esta separação do impulso de realização imediata do 
Contribuições da Teoria Histórico-Cultural para o Processo de Avaliação...

ato, constituindo o mecanismo que prepara a ação futura. É a inclusão de operações simbólicas que torna possível a formação de um campo psicológico absolutamente novo, um campo que não se apóia no presente existente, mas em esboços da situação futura da ação, criando a ação livre independente da situação imediatamente efetiva (Vigotski \& Luria, 1994).

Para Vigotski e Luria (1994), geneticamente, as funções superiores diferem dentro da filogênese por não serem produto da evolução biológica, mas do desenvolvimento histórico do comportamento, enquanto que, na ontogênese, elas têm também uma história social especial. Com respeito à estrutura, sua peculiaridade consiste em distinguir-se do reativo direto que estrutura os processos elementares, pois são construídas na base do uso de estímulo-meios (sinais) e, ao dependerem disto, refletem um caráter indireto. Finalmente, são caracterizadas como comportamento intelectual pelo uso funcional da fala e cumprem um papel novo e essencialmente diferente, se comparado às funções elementares, um papel que provoca uma adaptação organizada à situação.

Em resumo, o comportamento do homem é o produto do desenvolvimento de um sistema amplo de ligações sociais, de formas coletivas de comportamento e cooperação social e a história das funções psicológicas superiores é descrita por Vigotski e Luria (1994) como a história da transformação de meios de comportamento social em meios de organização psicológica individual. No processo de desenvolvimento geral, portanto, podem ser distinguidas duas linhas principais, qualitativamente diferentes: a linha de formação biológica do processo elementar e a linha da formação sóciocultural das funções psicológicas superiores, sendo que a verdadeira história do comportamento da criança nasce do entrelaçar destas duas linhas.

Somente entendendo a atividade do homem como desenvolvimento histórico-cultural do comportamento, pode esta ser considerada uma atividade livre, isto é, independente de necessidades diretas e da situação imediatamente percebida, ou seja, uma atividade engrenada para o futuro. Por isso, para Vygotski (1956), é a educação escolar - quando corretamente organizada - que permite à criança desenvolver-se intelectualmente, criando toda 
uma série de processos de desenvolvimento que seriam impossíveis sem ela. "A educação revela-se, portanto, um aspecto internamente necessário e universal do processo de desenvolvimento, na criança, das características históricas do homem, e não de suas características naturais” (Vygotski, 1956, p. 450). É a apropriação dos conhecimentos científicos, conforme discute Facci (2004), que possibilita o desenvolvimento das funções psicológicas superiores. Avaliar uma criança tendo como base esta perspectiva teórica é, portanto, também avaliar as condições que possibilitaram ou não o desenvolvimento dessas funções.

\section{Finalizando....}

Uma avaliação psicoeducacional adequada deve contemplar, portanto, uma análise do desenvolvimento infantil de modo prospectivo, indicando aquelas noções e conceitos que estão no nível de desenvolvimento próximo. É, justamente, sobre essas noções e conceitos, que deve centrar o ensino, a fim de serem desenvolvidas as funções psicológicas superiores.

De acordo com Vygotski (1995), ao investigar um fenômeno psicológico, deve-ser partir da análise do processo, e não do objeto; deve-se priorizar a análise explicativa e não descritiva; e deve-se utilizar a análise genética, que volta ao ponto de partida e restabelece todos os processos de desenvolvimento. Baseado em Marx, Vygotski (1995) afirma que se as manifestações externas do objeto coincidissem com as verdadeiras relações das coisas, não seriam necessários estudos científicos, pois a simples observação, a simples experiência cotidiana, a simples anotação dos fatos substituiria as análises científicas. É preciso compreender e analisar as relações internas dos fatos e não somente suas manifestações. Esse é um pressuposto que consideramos fundamental no processo de avaliação das funções psicológicas superiores. O método instrumental pode ser muito útil para o estudo das funções psicológicas superiores, pois significa aplicar as categorias do desenvolvimento à investigação dos fenômenos. 
Contribuições da Teoria Histórico-Cultural para o Processo de Avaliação...

Não há forma complexa, superior, de conduta cultural que não esteja constituída sempre por vários processos elementares e primários do comportamento, pois “... toda forma superior de conduta é impossível sem as inferiores, porém, a existência das inferiores ou secundárias não esgota a essência da superior” (Vigotski, 1995, p. 119). Nesse sentido, Vigotski enfatiza que é fundamental, nesse método, investigar os momentos iniciais do desenvolvimento das funções psicológicas superiores, numa perspectiva histórica, pois essas funções foram constituídas por diversos processos elementares e primários do comportamento. O principal aspecto do método de análise psicológico proposto por Vigotski é estudar a totalidade, as propriedades e funções das partes que a integram, não como somatória, mas a partir das propriedades particulares que a determinam e que se relacionam.

Um dos desafios educacionais da atualidade é, portanto, desenvolver procedimentos de avaliação dinâmica que utilizem os resultados e análises das descrições qualitativas dos processos de aprendizagem para produzir informações práticas adequadas aos programas instrucionais. Dessa forma, pode ser possível desenvolver uma teoria e uma prática da avaliação que aplique idéias derivadas da teorização de Vigotski sobre o nível de desenvolvimento próximo, possibilitando a avaliação minuciosa dos processos psicológicos, úteis para o planejamento educacional, considerando os dados acerca do processo de escolarização do aluno, e, principalmente, de seu contexto histórico-social. Assim, conhecer as potencialidades do aluno torna-se tão fundamental quanto considerar a prática social na qual se desenvolve a prática educativa, que produz o sucesso e o insucesso escolar, para se abarcar as múltiplas relações que constituem o desenvolvimento do psiquismo humano.

Se, de acordo com Saviani (2002), educação é mediação, isto significa que ela não se justifica por si mesma, mas tem sua razão de ser nos efeitos que se prolongam para além dela e que persistem mesmo após a cessação da ação pedagógica. Portanto, dado o caráter da educação como mediação no seio da prática social global, a relação pedagógica tem na prática social o seu ponto de partida e o seu ponto de chegada. Assim, o critério para se aferir o 
grau de democratização atingido no interior das escolas deve ser buscado na prática social e não no organismo individual.

Quando se considera, conforme Saviani, que o processo educativo se inicia em um processo de desigualdade para atingir um processo de igualdade, os conteúdos devem estar atrelados à prática social, oferecendo recursos para que os indivíduos entendam a realidade e potencializem uma transformação. Tal contribuição se consubstancia na instrumentalização, isto é, nas ferramentas de caráter histórico, matemático, científico, literário etc., cuja apropriação o professor seja capaz de garantir aos alunos e "tal contribuição será tanto mais eficaz quanto mais o professor for capaz de compreender os vínculos da sua prática social global” (Saviani, 2002, p. 80).

Neste sentido, a avaliação psicoeducacional precisa ir além da avaliação do aluno, de seus conhecimentos e competências como decorrentes de fatores orgânicos de desenvolvimento e maturação, precisa ser também uma avaliação da escola e de suas metodologias, dos conteúdos que esta oferece aos alunos, bem como da qualidade das mediações. Em suma, constitui-se numa avaliação que extrapola o âmbito psicoeducacional para o âmbito sócioeducacional, ao considerar a escola e a sociedade onde a criança está inserida, sendo menos excludente e seletiva e mais dinâmica, desenvolvimentista e revolucionária, como proposta por Vigotski e seus continuadores. Neste campo, no entanto, muito há para ser feito, no interior das Universidades e escolas, rompendo inclusive com a cisão entre pesquisa e prática psicopedagógica. Este artigo pretende somar esforços na direção destes objetivos. 
Contribuições da Teoria Histórico-Cultural para o Processo de Avaliação...

Facci, M. G. D., Eidt, N. M., \& Tuleski, S. C. (2006). Contributions from the historical-cultural theory to the psychoeducational assessment process. Psicologia USP, 17 (1), 99-124.

\begin{abstract}
This article presents contributions from the historical-cultural psychology to the critical analysis of the traditional psychoeducational assessment as well as postulating the basis for a new assessing modality. Such proposal is justifiable through the present revitalization of the usage of standardized testings to measure the psychological functions, due to the vulgarization of the neuropsychology. Historically, the standardized tests have been used to scientifically assert the ideology of equality among the people in the capitalist society which maintains itself through expropriation and exclusion. Besides, there is a strong tendency to hope for their results explain intelligence as innate or consider the hereditary predispositions to learn, which goes against the comprehension that the mental functions are formed in the historical-social development, through the appropriation of the human culture. Therefore, an assessment which considers the social mediations (instruments and signs) as components of the psychological functions is necessary, promoting development of every individual, and not legitimating the social exclusion.
\end{abstract}

Index terms: Educational psychology. Psychological assessment. Psychological testing.

Facci, M. G. D., Eidt, N. M., \& Tuleski, S. C. (2006). Contribution de la théorie historique-culturelle pour le proccès de l'évaluation psychoéducationnel. Psicologia USP, 17 (1), 99-124.

Résumé: Cet article a comme objectif présenter la contribution de la Psychologie Historique-Culturelle pour l'analyse critique de l'évaluation psychoéducationnel traditionnel et postuler les fondements pour la nouvelle modalité évaluative. Cette proposition se justifie à cause de l'actuelle révitalisation de l'usage des testes padronisés pour la mensuration des fonctions psychologiques, dues à la vulgarisation de la neuropsychologie. Historiquement les testes padronisés servent comme instrument pour attester cientifiquement l'idéologie de l'égalité entre les hommes dans la societé capitaliste que se maintient à travers de l'expropriation et de l'exclusion. En outre, il existe une forte tendence à attendre que les résultats expliquent l'intelligence comme inée ou considèrent les prédispositions héréditaires pour apprendre, ce qu’on oppose à la comprehénsion que les 


\title{
Marilda Gonçalves Facci, Nádia Mara Eidt e Silvana Calvo Tuleski
}

\author{
fonctions mentales sont formées dans le proccès de développement \\ historique-social à travers l'appropriation de la culture humaine. Il est \\ nécessaire donc une évaluation qui considère les médiations sociales (des \\ instruments et des signes) comme constituants des fonctions \\ psychologiques encourageant le développement de tous les individus et la \\ non légitimation de l'exclusion sociale. \\ Mots-clés: Psychologie pédagogique. Estimation psychologique. Essai \\ psychologique.
}

\section{Referências}

Alchieri, J. C., \& Cruz, R. M. (2003). Avaliação psicológica: conceitos, métodos e instrumentos. São Paulo: Casa do Psicólogo.

Angelucci, C. B., Kalmus, J., Paparelli, R., \& Patto, M. H. S. (2004, jan./abr.). O estado da arte da pesquisa sobre o fracasso escolar (1991-2002): um estudo introdutório. Educação e pesquisa, 30(1). Recuperado em 12 fev. 2006, da SciELO (Scientific Electronic Library OnLine): http://www.scielo.br

Beáton, G. A. (2001). Evaluación y diagnóstico en la educación y el desarrollo desde el enfoque histórico cultural. São Paulo: Cromosete.

Bissoli Neto, J. (1997). Legislação e situação atual das classes especiais no Estado de São Paulo. In A. M. Machado et al. (Orgs.), Educação especial em debate (pp. 5565). São Paulo: Casa do Psicólogo.

Campione, J. C. (2002). Avaliação assistida: uma taxonomia das abordagens e um esboço de seus pontos fortes e fracos. In D. Harry (Org.), Uma introdução a Vygotsky (pp. 255-292). São Paulo: Loyola.

Collares, C. A. L., \& Moysés, M. A. A. (1997). Respeitar ou submeter: a avaliação de inteligência em crianças de idade escolar. In A. M. Machado et al. (Orgs.), Educação especial em debate (pp. 117-136). São Paulo: Casa do Psicólogo.

Facci, M. G. D. (2001). Fundamentos teóricos e a psicologia nas escolas municipais de Maringá: uma visão crítica? Revista do Departamento de Psicologia da UFF, 13(1), 73-90.

Facci, M. G. D. (2004). Valorização ou esvaziamento do trabalho do professor? Um estudo crítico-comparativo da Teoria do Professor Reflexivo, do Construtivismo e da Psicologia Vigotskiana. Campinas, SP: Autores Associados. 
Contribuições da Teoria Histórico-Cultural para o Processo de Avaliação...

Leontiev, A. N. (1991). Os princípios do desenvolvimento mental e o problema do atraso mental. In A. R. Luria, A. N. Leontiev, L. S. Vygotsky, \& L. Semenovich, Psicologia e pedagogia: bases psicológicas da aprendizagem e do desenvolvimento (pp. 59-76). São Paulo: Moraes. (Trabalho original publicado em 1959)

Linhares, M. B. M. (1995, jan./abr.). Avaliação assistida: fundamentos, definição, características e implicações para a avaliação psicológica. Psicologia: Teoria e Pesquisa, 11(1), 23-31.

Lunt, I. (1994). A prática da avaliação. In H. Daniels, Vygotsky em foco: pressupostos e desdobramentos (pp. 219-252).Campinas, SP: Papirus.

Luria, A. R. (1957). Psychopathological research in the U.R.S.R. In Psychology in the Soviet Union (J. \& M. Ellis, trans., pp. 279-287). London: Routledge Kegan Paul. (Trabalho original publicado em 1955)

Luria, A. R. (1969). The neuropsychological study of brain lesions and restoration of damaged brain functions. In M. Cole \& I. Maltzman (Eds.), A handbook of contemporary soviet psychology: abnormal and social psychology (pp. 277-301). New York, London: Basic Books Publishers. (Trabalho original publicado em 1948)

Luria, A. R. (1994). The problem of the cultural behavior of the child. In The Vygotsky reader (T. Prout, trans., pp. 46-56). Cambridge: Blackwell Publishers. (Trabalho original publicado em 1928)

Luria, A. R., \& Majovski, L. V. (1977, Nov.). Basic approaches used in American and Soviet Clinical Neuropsychology. American Psychologist, 32(11), 959-968.

Machado, A. M. (2000). Avaliação psicológica na educação: mudanças necessárias. In E. R. Tanamachi, M. L. Rocha \& M. P. R. Proença (Orgs.), Psicologia e educação: desafios teórico-práticos (pp. 143-167). São Paulo: Casa do Psicólogo.

Mindrisz, R. K. (1994). A tirania do QI: o quociente de inteligência na caracterização do indivíduo deficiente mental. Dissertação de Mestrado, Pontifícia Universidade Católica de São Paulo, São Paulo.

Saviani, D. (2002). Escola e democracia. Campinas, SP: Autores Associados. (Trabalho original publicado em 1983)

Souza, M. P. (1997). A queixa escolar e o predomínio de uma visão de mundo. In A. M. Machado \& M. P. Souza (Orgs.), Psicologia escolar: em busca de novos rumos. (pp.17-34). São Paulo: Casa do Psicólogo.

Vygotsky, L. S. (1982). Collected works (M. J. Hall, trad.). Moscou: Progress. (Trabalho original publicado em 1930) 
Marilda Gonçalves Facci, Nádia Mara Eidt e Silvana Calvo Tuleski

Vygoski, L. S. (1995). Obras escogidas (A. Alvarez \& P. Del Rio, trads., Vol. 3). Madrid: Centro de Publicaciones del M.E.C. y Visor Distribuciones. (Trabalho original publicado em 1931)

Vygotsky, L. S., \& Luria, A. R. (1994). Tool and symbol in child development. In The Vygotsky reader (T. Prout trans., pp. 99-174). Cambridge: Blackwell. (Trabalho original publicado em 1930)

Vygotsky, L. S., \& Luria A. R. (1996). Estudos sobre a história do comportamento: símios, homem primitivo e criança. (L. L. de Oliveira, trad.) Porto Alegre: Artes Médicas. (Trabalho original publicado em 1930)

Recebido em: 12.06.2006

Aceito em: 26.06.2006 